\title{
Driving towards a greener future: an application of cognitive work analysis to promote fuel-efficient driving
}

\author{
Neville A. Stanton ${ }^{1}$. Craig K. Allison ${ }^{1}$ (1) \\ Received: 19 July 2018 / Accepted: 25 March 2019 / Published online: 8 April 2019 \\ (c) The Author(s) 2019
}

\begin{abstract}
Driving is a daily encountered task for many. Unlike the majority of life's daily hassles, however, the act of driving has significant environmental repercussions. Supporting the development of environmentally conscious driving techniques and developing tools and interfaces to reduce the environmental impact of driving is warranted to minimise the negative impact of these actions. The current paper documents the development of a complete cognitive work analysis (CWA) to support environmentally conscious driving. The paper proposes that the use of the CWA approach-enabled examination of the fuelefficient driving task and consideration of the role numerous objects, agents and skills can play in facilitating fuel-efficient driving. In addition to the traditional CWA process, this paper shows how the revealed finding can be used as the basis for developing specifications that can be taken forward to allow for the development of novel in-vehicle interfaces to support fuel-efficient driving.
\end{abstract}

Keywords Cognitive work analysis $\cdot$ Eco-driving $\cdot$ Pervasive technology $\cdot$ Fuel-efficient driving

\section{Introduction}

Anthropometric climate change is, and will continue to be, a defining truth of the twenty-first century (Thornton and Covington 2015). Greenhouse gases (GHG), for example, carbon dioxide $\left(\mathrm{CO}_{2}\right)$ and nitrous oxides $\left(\mathrm{NO}_{x}\right)$ generated by human action, for example, transport and manufacturing, play a key role in influencing global temperature and weather conditions. Whilst it can be difficult for individuals to see the impact of their own behaviour, approximately $30-40 \%$ of total GHG emissions can be directly attributed to individual energy needs supporting twenty-first-century western lifestyles (Vandenbergh et al. 2007). Overall emissions can, however, be significantly reduced if individuals modify their behaviour to act in a more environmentally friendly manner (Dietz et al. 2009).

Electronic supplementary material The online version of this article (https://doi.org/10.1007/s10111-019-00554-7) contains supplementary material, which is available to authorized users.

Craig K. Allison

Craig.Allison@soton.ac.uk

1 Transportation Research Group, Faculty of Engineering Environment, University of Southampton, Boldrewood Innovation Campus, Southampton SO167QF, UK
Transport is a prolific source of pollution, especially GHG emissions. In the European Union (EU), the quantity of GHG emitted directly as a consequence of transport comes second only to electricity generation (Hill et al. 2012). Road transportation, typically personal cars, is the highest contributor to this statistic, accounting for approximately $75 \%$ of all transport GHG emissions (Hill et al. 2012). Similar patterns of emissions can be seen in the United States of America, whereby car use accounts for between 32 and $41 \%$ of the USA's total $\mathrm{CO}_{2}$ emissions (Vandenbergh and Steinemann 2007; Bin and Dowlatabadi 2005). Barkenbus (2010) estimates that approximately $8 \%$ of the worlds' current $\mathrm{CO}_{2}$ emissions are a result of transportation. Minimising transportation-, and specifically automobile-related emissions, should, therefore, be considered as a low-hanging fruit to reduce current levels of GHG emissions. Due to the vast number of road vehicles currently active, with the UK alone, has an estimated 30.3 million privately cars on the road [Department of Transport Vehicle Licensing Statistics: Quarter 4 (Oct-Dec) 2015], small-scale savings made within this sector can have a significant impact.

Whilst limiting the number of car journeys would be the most dramatic way to reduce automotive vehicle-related GHG emissions (Strömberg et al. 2015), this approach is not viable. Two alternate approaches can, however, enable 
the use of cars whilst reducing fuel use and emissions. The first approach is the development and implementation of new in-vehicle technology and fuel-efficient drivetrains than those currently available. Improvements in vehicle drivetrain efficiency can be seen when considering hybrid and plug in hybrid electric vehicles, such as the Toyota Prius, Nissan Leaf and Mitsubishi PHEV. These vehicles use developments in technology to reduce emissions and achieve greater fuel efficiency, with Mitsubishi PHEV claiming to achieve 157 miles per gallon, considerably greater than similar internal combustion engine (ICE) vehicles. The second approach is modifying driver behaviours, to encourage the adoption of fuel-efficient, eco-driving techniques. Barkenbus (2010) proposed that eco-driving is characterised by behaviours such as modest acceleration, early gear changes, limiting the engine to approximately 2500 revolutions per minute (RPM), anticipating traffic flow to minimise breaking, driving below the speed limit, and limiting unnecessary idling. A key advantage of encouraging eco-driving behaviours is that these techniques can be employed by all drivers, and are not reliant on significant financial investment, such as would be necessary to purchase a new vehicle, with a more fuel efficient drivetrain. Consequently, encouraging eco-driving is an appropriate technique for owners of older cars and those with limited disposable income. Although eco-driving training has been demonstrated to offer significant fuel saving benefits (Wu et al. 2017), it is also clear that many drivers do not engage in such behaviors, despite previous awareness of eco-driving techniques (Pampel et al. 2017). Previous work (Allison and Stanton 2019; Mcllroy et al. 2013) has highlighted that eco-driving should be supported and encouraged regularly via the use of in-vehicle interfaces to maintain long-term effectiveness. Identifying the constraints that operate around car-use and driving behaviours can enable the informed development of low-cost interfaces supporting the maintenance of such behaviours.

In-car interfaces can be implemented to facilitate drivers' awareness of their current behaviours (Oinas-Kukkonen and Harjumaa 2009) as well as support and train drivers to engage in more environmentally friendly driving behaviours (Tulusan et al. 2012). The adoption of eco-driving behaviours can lead to a reduction in fuel use and subsequently a reduction of $\mathrm{CO}_{2}$ and $\mathrm{NO}_{x}$ emissions. Such interfaces have received positive reviews, for their potential in reducing GHG emissions (Carsten and Tate 2005), but concerns relating to their use have arisen due to the possible negative implications they can have on safety due to potential for such displays to distract drivers (Cacciabue and Saad 2008; Young et al. 2011). Due to this dichotomy, a focus on the design of potential interfaces is considered a priority for research in a variety of transport interface research fields, commonly following a users' centred design approach (Cacciabue and Martinetto 2006; Fénix et al. 2008).

\subsection{Cognitive work analysis}

Cognitive work analysis (CWA) is a framework for understanding complex socio-technical systems, characterised by close interactions of people and technology (Stanton and Bessell 2014). Originally developed for use in the nuclear power industry (Rasmussen 1986), it has been suggested that CWA can act as a key tool when developing and designing novel systems (Rasmussen et al. 1990). CWA seeks to understand the constraints that frame a working system, understanding what is required of the system as well as what is both possible and not possible within the confines of the system (Kant 2017). By focusing on the constraints, the analysis seeks to understand and support worker needs for improved efficiency and safety (Stanton et al. 2013). CWA has been used for understanding a variety of complex systems including military planning systems (Jenkins et al. 2008; Stanton and McIlroy 2012), team design (Naikar et al. 2003), the aviation domain (Stanton et al. 2016) and even the Apple iPod personal music device (Cornelissen et al. 2013). Drawing upon foundations in ecological psychology, general systems thinking and adaptive control systems (Fidel and Pejtersen 2004), CWA has developed into a domain agnostic and highly flexible method that can be utilised to understand both current work domains and explore the potential of future developments. Naikar and Lintern (2002) suggest that CWA is an ideal method for envisioning revolutionary design as it allows a focus on the fundamental requirements of the system. CWA is an appropriate method for the challenge of supporting eco-driving behaviours as it can be used for both systems design of and inform the design of future human-machine interfaces (van Westrenen 2011). Indeed, previous work has used independent components of the CWA process to support eco-driving including developing an abstraction hierarchy (Birrell et al. 2012) and decision ladders (McIlroy and Stanton 2015a).

The complete CWA process comprises of five key phases, work domain analysis (WDA), control task analysis (ConTA), strategies analysis (StrA), social organisation and cooperation analysis (SOCA) and worker competencies analysis (WCA) (Vicente 1999; McIlroy and Stanton 2011). The primary focus of the WDA is the development of an abstraction hierarchy. The abstraction hierarchy aims to map the proposed system on multiple conceptual levels, ranging from it reason for existing to the physical objects that comprise the system (Naikar 2013). Control task analysis examines the constraints that operate on a system within set conditions. ConTA can be seen as defining the available inputs and end goal of a system (Naikar 2006). The common tool for ConTA is that of the decision ladder (Vicente 1999), and examines the steps, and potential 
shortcuts, a user follows when operating a system. Phase 3 is the StrA component. It has been argued (Naikar 2006) that the strategies individuals use to operate a system can vary significantly under different operating conditions, for example, as a result of time pressure or during highstress situations, such as a safety critical event. StrA often takes the form of flow maps, defining start and end states of the system and describing the potential tasks required to transform the system for the start to the desired end state (Ahlstrom 2005; Naikar 2006). The fourth phase of CWA, SOCA, examines the allocation of tasks within the system, accounting for both human and technological agents on an equal level (Vicente 1999). SOCA maps the responsibility of given tasks to different actors and acts as a way reallocate tasks to improve efficiency and safety. The dynamic allocation of function can be applied to all elements of the CWA process, including the abstraction hierarchy, CAT, StrA and the worker competency analysis (WCA). The final phase of the CWA framework is the WCA. Kilgore and St-Cyr (2006) suggests that this stage of CWA focuses on psychological constraints of the users of systems. Worker competency analysis often draws upon the Skills, Rules and Knowledge taxonomy (SRK; Vicente 1999) to map out the level of cognitive effort applied to the different tasks.

Despite the final outcome of the CWA analysis not being a complete workable design of the envisaged system or interface, it is argued that mapping the constraints and requirements can produce a final system more suitable to end-user requirements, reducing the need for future iterative design stages (McIlroy and Stanton 2011). CWA offers analysts a technology agnostic approach to consider a system, allowing for the consideration of both technology and human agents in the same analysis (Vicente 1999; Jenkins et al. 2008). This makes it an ideal approach for the development of novel technology as well as a tool to consider the constraints for a new addition or interface within a previously established domain. Driving is one such domain whereby drivers must interact with in-built vehicle mechanical systems, other road users and, increasingly, in-vehicle technology, such as driver-assist technology. This paper will document the development of a CWA to support fuel-efficient driving and lay down the design constraints necessary to develop interfaces that support fuel-efficient driving.

\section{Method}

Whilst a complete CWA can be seen as an extensive and time-consuming task, requiring numerous iteration and consultation, individual elements of the CWA process can be completed independent of the full analysis and subsequently refined and validated (McIlroy and Stanton 2011).
Lintern et al. (2004) argued that the WDA component of CWA provides an ideal starting point. As the key outcome of the WDA is the abstraction hierarchy, initial focus was given to the development of this metric. Although previous research (Birrell et al. 2012) produced an abstraction hierarchy mapping eco-driving, considerable technical developments have occurred within the automotive sector since this prior work was completed, including considerable progress relating to the development and large scale adoption of hybrid vehicles. It was, therefore, deemed prudent to reconsider this work in light of these technical developments.

The abstraction hierarchy was created over the course of a daylong workshop with a series of academics with a research interest in automotive fuel efficiency. Research participants comprised of nine academic staff from the University of Southampton, University College London and Imperial College London. Participants were aged between 27 and 57 years $(M=36.3, \mathrm{SD}=10.8)$ and all held doctoral degree level qualifications within their respective fields of expertise. The workshop drew together individuals with an extensive knowledge of vehicle dynamics, control engineering, drivetrain optimisation, traffic operations, eco-driving and fuel usage. The attendees held a mixture of backgrounds, including Engineering, Human Factors and traffic modelling. This enabled a consideration of factors that would be unknown to any single member of the team. As Sharp and Helmicki (1998) suggest, CWA is heavily dependent on the skills and knowledge of the analysts and the resources at their disposal. Analysts understanding and knowledge of the system functioning are, therefore, key in developing a useful and complete CWA. To facilitate the workshop, two members of the team had extensive knowledge and experience of the CWA process.

Following the initial workshop, the abstraction hierarchy was formally constructed based upon ideas discussed during the workshop and remaining links between different elements generated by the human factors team. The initial workshop team subsequently validated the generated links and elements during a follow-up workshop. For the validation exercise, each team member was presented with the completed abstraction hierarchy, including the completed means-end analysis, and was asked to exhaustively check each object and link with the hierarchy. To facilitate this process, each workshop participant was presented with a matrix of each level pairing from the abstraction hierarchy, for example "functional purpose" paired with "values and priorities" and asked to mark within the matrix whether each of the current connections were valid or whether a new connection was needed. Following this process, each modification, i.e. removal or addition of connections, was discussed in depth with the wider team and group consensus was reached for each paring. 
Once the agreed upon abstraction hierarchy was validated, the remaining CWA phases were completed independently by the human factors team and subsequently validated by the larger workshop team upon the completion of each stage.

\section{Results and discussion}

\subsection{Work domain analysis}

When constructing an abstraction hierarchy for fuel-efficient driving, the primary identified functional purposes of the system were "save energy" and "reduce emissions $\left(\mathrm{CO}_{2}\right.$ and $\mathrm{NO}_{x}$ )". A third potential functional purpose was added, "getting from A to B"; however, questions were raised by members of the team whether this was a function of the proposed device or a by-product of being a device designed to operate within a car. Although consensus was reached, with the majority of the workshop team, it was a considerable point of discussion. The group continued to discuss the values and priorities layer, the metrics for identifying whether develop device would be successful at its previously defined functional purposes. Eight values and priorities were identified, "optimise vehicle range"; "reduce fuel usage"; "minimise traffic delay"; "minimise congestion"; "optimise driver satisfaction"; "optimise travel time"; "reduce $\mathrm{NO}_{x}$ "; and "reduce $\mathrm{CO}_{2}$ ".

Rather than continuing the top-down approach, which had driven the discussion up to this point, the team switched to a bottom-up strategy to discuss the physical objects that would be required by the potential system and elements which the system could interact with. This primarily included sensors which the vehicle would need to be aware of its surrounding environment, power systems and drivetrain to propel the vehicle, direct vehicular controls and ancillary systems which require energy to operate, but are not part of the fundamental requirements for vehicle motion, for example, air condition and heating.

Once the physical objects within the system had been defined, the team progressed to discuss the object related properties layer within the hierarchy. This layer focuses primarily on the function of the physical objects of the system, for example "air conditioning", a physical object, influences "cabin temperature" and controls "cabin humidity". The development of the object-related properties layer was also key in identifying physical objects that had not been initially considered, prompting further discussion.

The final stage to be completed was the PurposeRelated Functions. This layer seeks to bridge the objective elements of the hierarchy with the larger gestalt aims of the system under investigation. The functions identified related to identifying "road attributes" "objects in the world" "control vehicle motion" and ensuring "driver comfort" and "passenger comfort".

The complete abstraction hierarchy is presented within Online Appendix 1. The complete list of items that abstraction hierarchy is comprised of is presented within Table 1 for clarity. In addition, the purpose of each physical object, and its corresponding impact on fuel usage are presented in Table 2, alongside a corresponding reference. To test the suitability and completeness of the identified abstraction hierarchy, an exhaustive means-ends analysis was completed following the why-what-how triad approach (Rasmussen et al. 1994; Vicente 1999). Within the abstraction hierarchy, it possible to nominate any item within the matrix and as ask the question "what does this do?". When considering all connections in the layer immediately above the node it is possible to answer the question "why does it do this?". When considering all connections in the layer immediately below, it is possible to answer the question "how does it achieve this?" This ensured that all required connections were adequately captured and addressed. Following this analysis, the final abstraction hierarchy was produced. Due to the number of items and connections that were identified within the abstraction hierarchy, Fig. 1 presents a subsection of the abstraction hierarchy exploring the connections and affordances of the physical object "GPS" to illustrate the connections which exist.

Taking the physical object of in-vehicle GPS, this object can be used to afford knowledge of the most "fuelefficient path" to a given destination, the "shortest path", in terms of distance, to a given destination, and the "fastest path" to a given destination, in terms of travel time. The GPS system also affords the ability to "detect infrastructure", including traffic lights, junction, roundabouts and speed limits, as each of these factors will influence the potential paths the vehicle can take. Knowledge of vehicle paths, be it most fuel efficient, shortest or fastest, are linked to "road attributes" and constrained by "objects in the world". The ability to detect infrastructure is linked to knowledge of "objects in the world". If a system has knowledge of road attributes, and objects in the world, which could, potentially include other road users, it will be possible to generate a route that "minimises congestion", "minimises fuel use", "minimises traffic delays", "optimises vehicle range", "optimises driver satisfaction" and "optimises traffic time". Because of these advantages, the system assists the driver in completing their journey and "get from A to B", but also "save energy" and "reduce emissions $\left(\mathrm{CO}_{2}\right.$ and $\left.\mathrm{NO}_{x}\right)$ )". Similar thought processes can be applied to every object within the abstraction hierarchy to generate the complete set of links through each of the physical objects to the overall functional purposes of the system. 
Table 1 Object related processes and physical objects identified within the abstraction hierarchy
Functional purposes

Values and priorities

Purpose related function

Object related processes
Save energy

Reduce emissions $\left(\mathrm{CO}_{2}\right.$ and $\left.\mathrm{NO}_{x}\right)$

Getting from A to B

Optimise vehicle range

Reduce fuel usage

Minimise traffic delay

Minimise congestion

Optimise driver satisfaction

Optimise travel time

Reduce $\mathrm{NO}_{x}$

Reduce $\mathrm{CO}_{2}$

Detect and present road attributes

Detect and present objects in the world

Control vehicle motion

Provide motive force

Support driver comfort

Support passenger comfort

Display vehicle speed

Display vehicle RPM

Control cabin humidity

Alert of hazards

Detect traffic jams

Provide information on other vehicle behaviours

Hold knowledge of most fuel efficient path

Understand own vehicle position

Understand own vehicle motion

Detect other road users

Hold knowledge of weather condition and forecast

Hold knowledge of shortest path

Hold knowledge of fastest path

Detect pedestrians

Control lighting

Hold knowledge of road gradient

Hold knowledge of road width

Detect infrastructure

Present speed limit

Present information on traffic lights

Control acceleration

Control vehicle speed

Control vehicle lane position

Control vehicle heading

Control vehicle headway

Present vehicle path

Provide a path

Provide energy

Control temperature of cabin

Provide information on range

Predict closure of roadway

Detect speed of other vehicles

Smooth motion

Detect distance of other vehicles

Maintain road adherence

Provide information on intersections

Provide information on road curvature

Present battery (state of charge)

Present battery (state of health) 
Table 1 (continued)

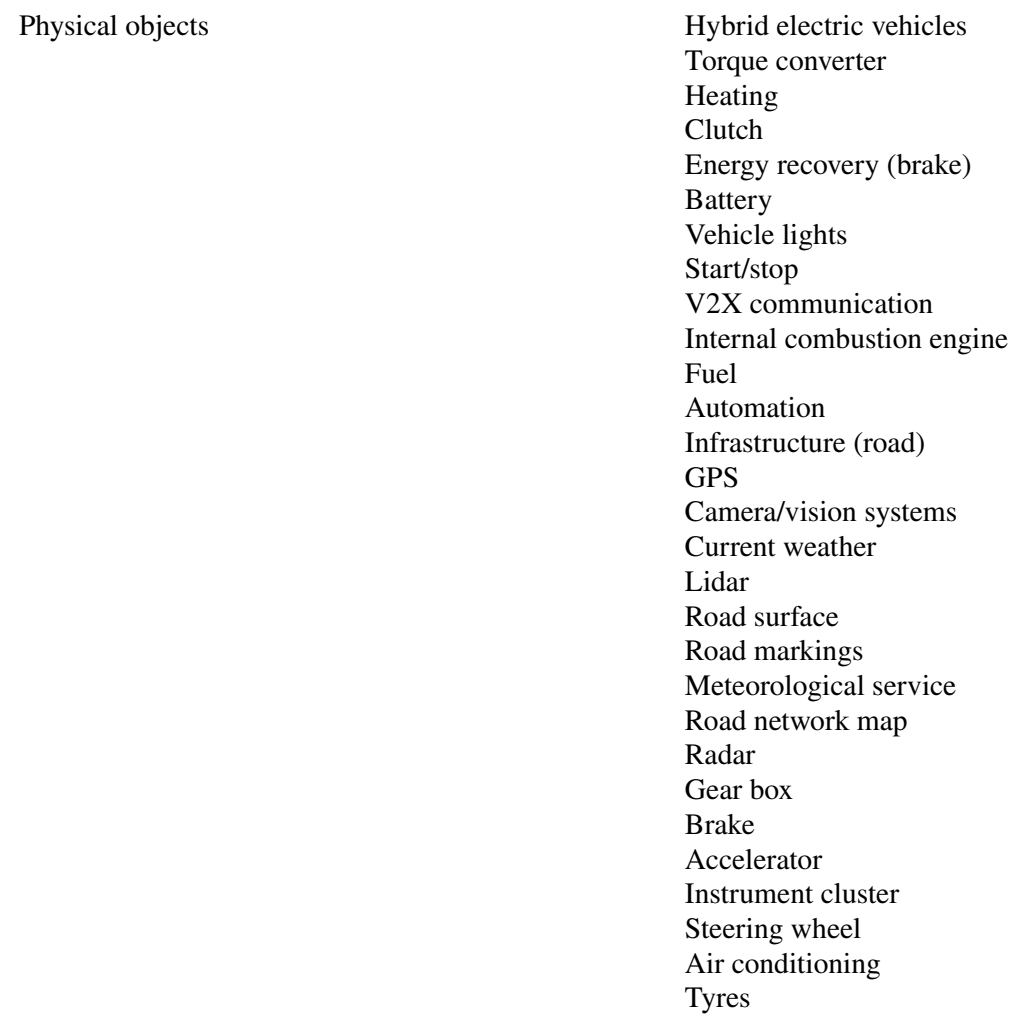

\subsection{Control task analysis}

The ConTA builds on the ideas presented within the WDA, to consider temporal constraints on a system, that is, when key activities using the system would take place. A common tool for achieving this goal is the contextual activity template (CAT; Naikar et al. 2006). The key objective of the CAT is to identify whether a task is typically completed within a given situation, whether a task can be completed within the situation, or whether the task is not possible within the situation. Within this framework, the work functions of a system are compared across considered across multiple potential situations, which may be as a consequence of spatial or temporal constraints (Rasmussen et al. 1994; Naikar et al. 2006). Defining appropriate work functions, however, can be a great challenge. Although a departure from traditional CWA approaches, Stanton and Bessell (2014) suggest that the object-related processes, identified within the abstraction hierarchy, are suitable for the definition of systems work functions. Whilst this may not hold true within large-scale systems with multiple supervisory operators, within the context of driving with a single operator, this approach was deemed appropriate and has been adopted within the current analysis. To achieve this goal, a matrix was developed whereby each Object-Related Process identified within the abstraction hierarchy was plotted against a variety of road situations that a driver could be faced with. The matrix was then overlaid with box and whisker plots to map whether the object-related process could be completed in the given situation. A box within a cell represents that the task can be completed within the situation; a circle or whisker indicates that an activity can be performed within the current situation and typically is and a cell with no markings indicates that an activity is not possible with the situation.

The development of the situations that would be considered was a key undertaking within this stage of the analysis. Situations that were initially considered were based on the generic road types that a driver could experience, including motorway (clear), motorway (congested), urban, and countryside. It quickly became apparent, however, that road type was largely not a key determinant factor to the identified object-related processes. Although minor differences were observed, for example, traffic lights are not present within motorway driving, the majority of driving-related tasks are independent of road type. A key example of this is the object-related process "Control vehicle heading", controlling vehicle heading is important for all scenarios where the vehicle is in motion, and not limited to a specific road type. To overcome this limitation, the holistic nature of a car journey was considered. The analysis was, therefore, widened to include specific journey scenarios, which could be encountered during a standard drive, including traveling on a motorway slip road and being on a roundabout. Figure 2 presents an excerpt of the completed CAT analysis 


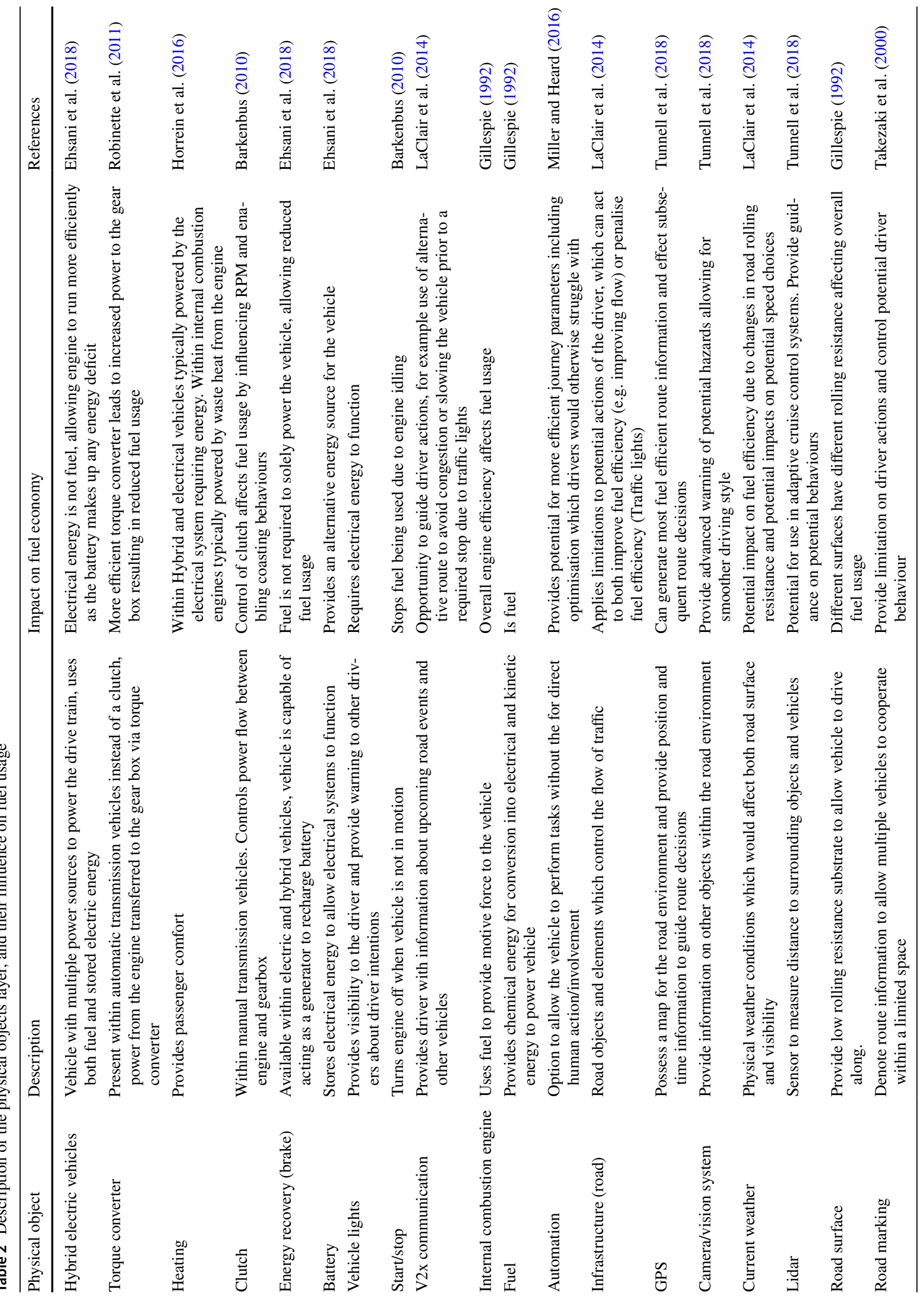




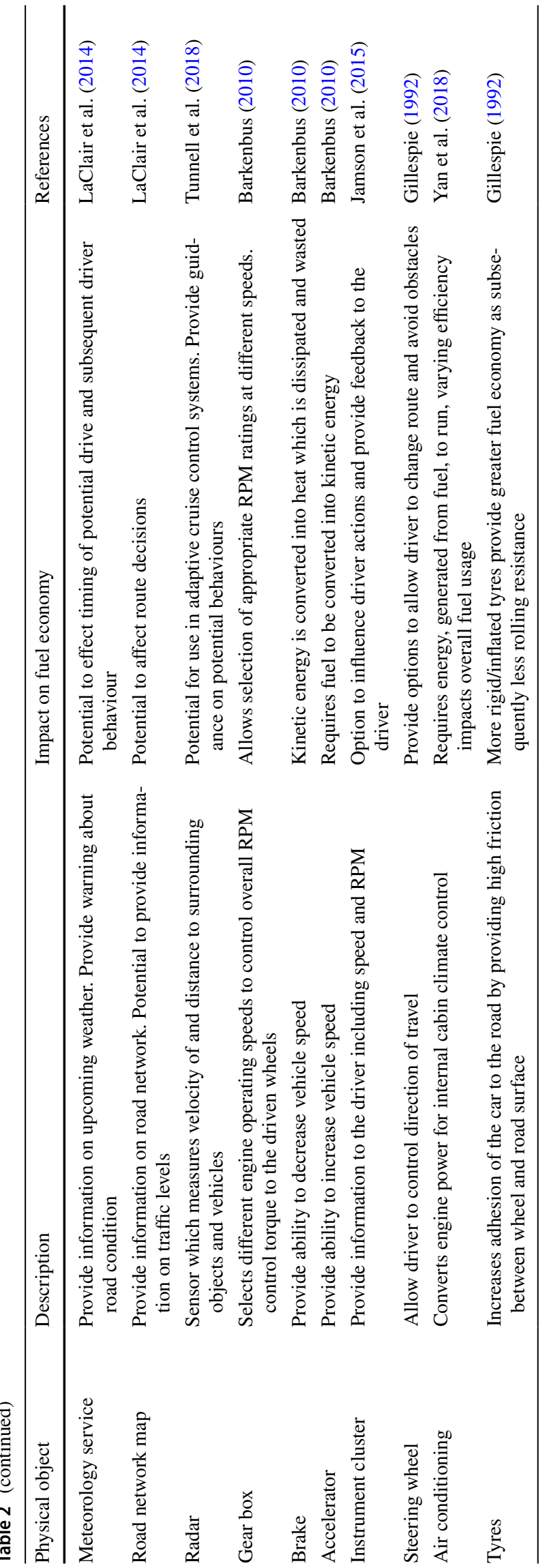

demonstrating the different situations a driver could find themselves in. The complete CAT analysis is presented within Online Appendix 2. In total, 23 different situations were considered, motorway clear; motorway congested; urban; major a-road; country road; junction; rural; residential; planning journey; in-car pre engine start; waiting at traffic lights; waiting at a junction; on a slip road; post journey, engine turned off; pre journey, engine started, handbrake on; on a roundabout; initial acceleration from stationary; cruising/steady speed; overtaking; parking; emergency stopping; reversing; and general braking.

From Fig. 2, it can bee seen that for the tasks of "display vehicle speed", "display vehicle RPM", "alert of hazards", "detecting traffic jams", "providing information on other vehicle behaviours", "own vehicle position", "own vehicle motion" and "other road users" are all typically applicable to the situations of driving on "motorway (clear)", "motorway (congested)", "urban", "major a-road", "country road", "junction", "rural" and "residential", however, are not experienced when a driver is initially planning their journey. The task of most fuel-efficient path, however, can occur in all of the aforementioned scenarios, including "Planning Journey". The task of "Traffic Lights" is also different as traffic lights do not appear motorways, and consequently cannot be encountered during this situation. Whilst traffic lights do not typically appear on major A-roads, traffic lights can be encountered on this road type. Traffic lights also are not encountered when planning a journey.

The CAT analysis highlighted how important the majority of the identified object-related processes are to the general task of driving. This finding was not initially anticipated, and although it could be argued such a finding makes this analysis superfluous, it is useful when considering the value of presenting situation tailored information. The analysis revealed how key vehicle metrics available to the driver are independent of the immediate need. One example of this is "display vehicle speed", which is available to the driver in all situations post engine start, including when the vehicle is stationary, and hence has no recorded speed and speed information is unnecessary. With the greater use of LCD displays within vehicles, future development could be influenced by knowledge of current context, supported by vehicle information data, including speed and on-board GPS and by the potential of V2X communication. The push for contextdriven information has been supported within previous work exploring drivers' information desires (Davidsson and Alm 2014). Across a series of interviews with 33 drivers, Davidsson and Alm (2014) found that information which drivers ranked as highly important in one context was not required in a different context. Taken together with the results of the current study, leveraging the role of context could play a central role in supporting fuel-efficient behaviours. 


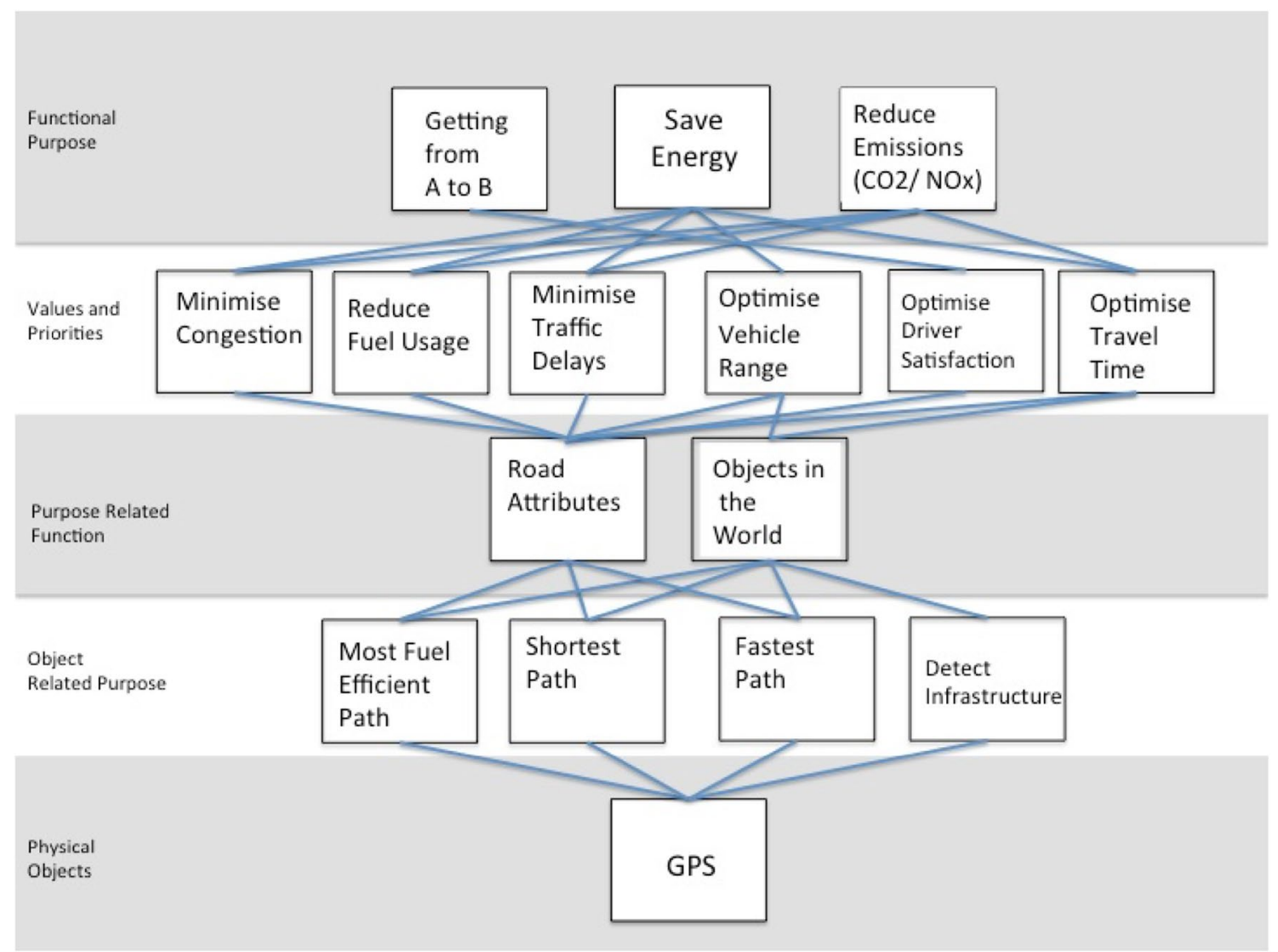

Fig. 1 Excerpt from the completed abstraction hierarchy

It is typical to progress the insights of the ConTA at this point to consider constraints in terms of decision-making processes. This analysis is typically achieved using decision ladders (Vicente 1999). The decision ladder presents a linear sequence of information processing steps, with novices following a linear process through all the steps and expert users able to make cognitive shortcuts through the steps. Whilst this stage would present a valuable addition to the current work, extensive work exploring the decisions ladders approach within eco-driving has already been completed (Mcllroy and Stanton 2015a). Due to the depth of this analysis, there is little need within the current analysis to revisit this topic area within the current study. The decision ladders developed by McIlroy and Stanton (2015a) were, therefore, used within the current study when progressing through the remaining CWA stages.

\subsection{Strategies analysis}

To progress through the StrA component of the CWA process, a series of simplified flow maps (Ahlstrom 2005) were produced. Although the use of extensive flow diagrams has been recommended for this stage of the investigation (Vicente 1999), the lack of clear guidance in how these should be produced and a lack of tools to facilitate the process hamper the adoption of this approach. Simplified flow maps are designed to present the strategies that individuals can use to achieve a set goal. Where appropriate, an individual may have access to different strategies at different times, dependant on external factors, for example, time constraints or accessibility of required tools. Simplified flow maps were created for the tasks of deceleration, acceleration, managing headway and maintaining current speed. The developed flow maps were based upon the decision ladders presented by (McIlroy and Stanton 2015a), and validated by the initial workshop team upon completion. The developed flow maps are presented within Online Appendix 3. As an example, Fig. 3 presents the simplified flow map for the scenario of deceleration to a lower speed.

As can be seen from this simplified flow map, once the driver has identified the need to decelerate to a lower speed, they can take three actions to achieve their goal.

1. Directly applying force to the brake pedal, allowing the vehicle to rapidly decelerate. 


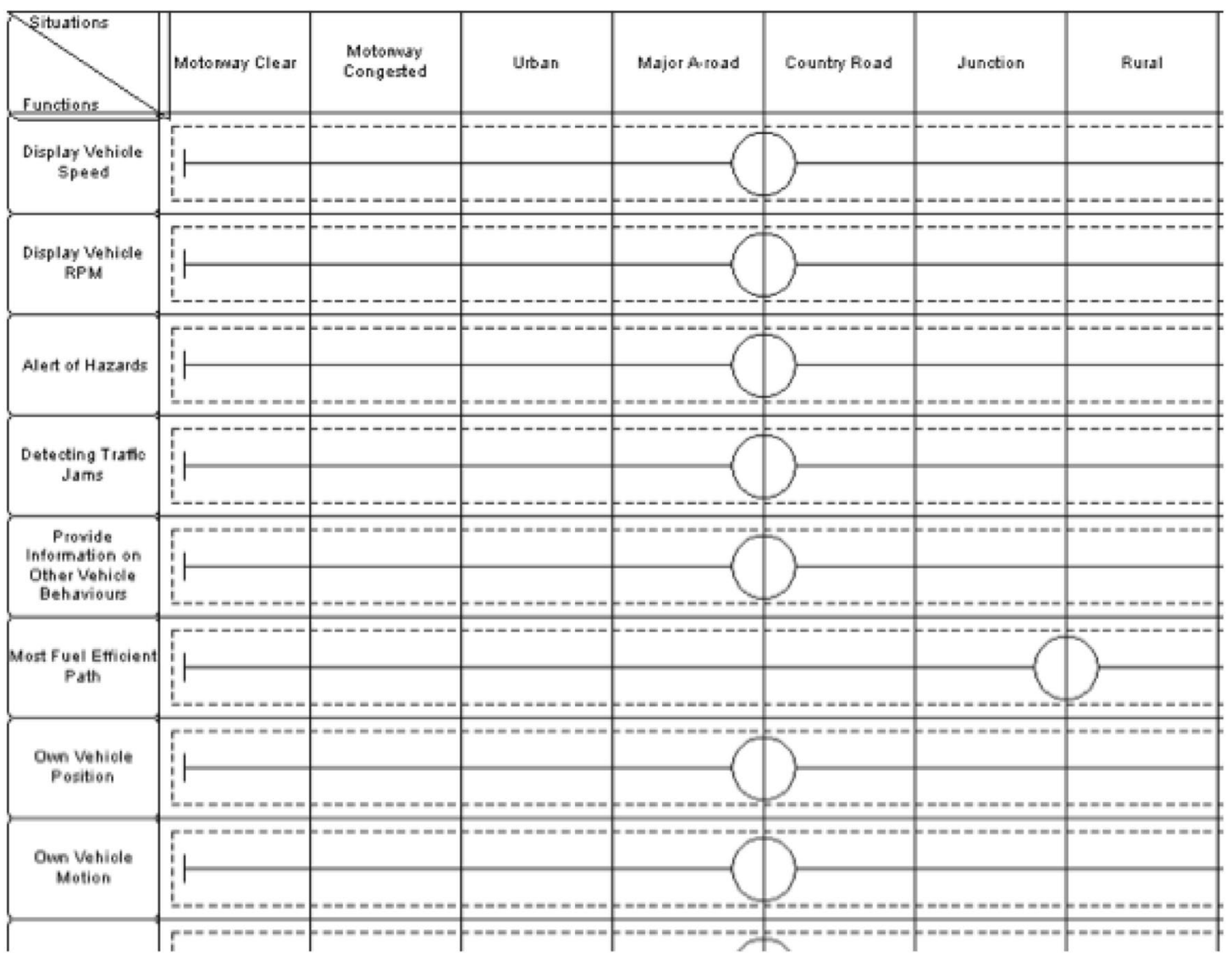

Fig. 2 Excerpt from the completed CAT analysis

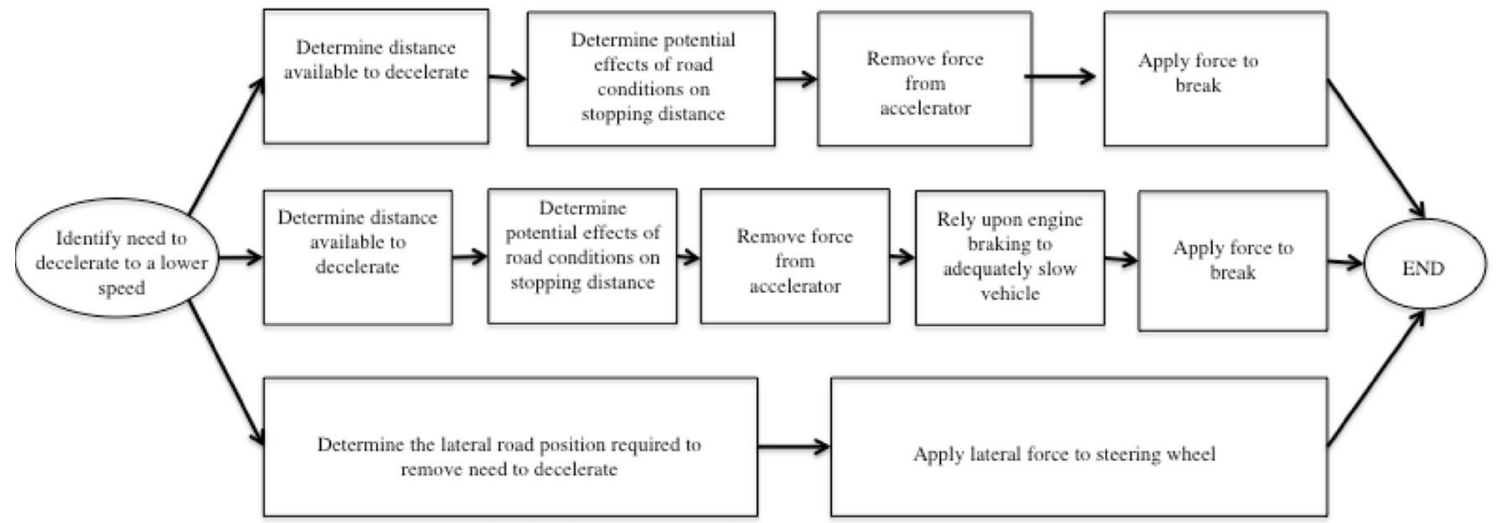

Fig. 3 Simplified flow map for the task of deceleration to a lower speed

2. Remove force from the accelerator pedal and rely upon engine braking to gradually slow the vehicle. The driver will consequently only apply force to the brake pedal when absolutely necessary to maintain required headway.
3. Determine that a deceleration would not be required if the vehicle was in a different lane of the road, and acting to change the vehicle's lateral position. 
For both actions whereby the vehicle maintains it current heading, the fundamental procedural requirements are consistent. The driver must remove force from the accelerator pedal and may have to, depending on distance available, apply pressure to the brake pedal. Fuel use in this context is related not to the mechanical actions that the driver takes, which due to their prescribed nature cannot significantly vary, but rather relate to the forces applied and the timings of the drivers' actions. By alerting drivers to the need to react to a potential hazard earlier, possibly due to the use of V2X communication, identified within the abstraction hierarchy, drivers will be able to rely more on engine braking to slow the vehicle, reducing the need to apply force to the brake pedal, therefore mitigating the need to take further actions. This offers support for the need for context aware interfaces and interventions that can inform the driver of upcoming actions that may be required, as identified within the CAT analysis, reducing the need for braking and improving overall fuel efficiency.

\subsection{Social organisation and cooperation analysis}

The CWA evaluation continued to examine and complete a SOCA. SOCA seeks to identify which agents, both human and non-human, can control and influence a situation (Houghton et al. 2015). SOCA can be seen as a way to map the agents who have responsibilities within different work situations. Multiple actors can influence or constrain a situation, be this sequentially or simultaneously, supporting distributed working. Although it has been argued that SOCA can play an important role when considering initial allocation of tasks, it can also be useful for considering which tasks can be reallocated in existing systems to improve usability and efficiency, for example away from a human operator and towards automation (Naikar et al. 2006). Whilst no specific tool for SOCA has been developed (Vicente 1999), it is widely accepted that this stage should build on previous work completed during the CWA investigation, as such for the current study, SOCA was completed as an annotated CAT.

For the current CWA, nine agents were identified as playing a role in fuel efficient driving; "driver", "on-board computers", "on-board displays", "on-board sensors", "infrastructure network", "other road users", "vehicle mechanical systems", "vehicle electrical systems", and "the law". These actors were considered for each of the object-related processes identified within the abstraction hierarchy and for the situations identified within the CAT. The role of two additional actors was discussed amongst team members at length, that of Pedestrians and Passengers. Pedestrians were discussed in relation to the specialist nature of pedestrians in affecting road vehicles and traffic flow; however, it was agreed that, for the considered situations, pedestrians could be classed as "Other Road Users" and were, therefore, not included in the final analysis. The role of "Passengers" was also discussed as a possible actor within the system, as passengers could influence a driver's actions, both positively, for example, alerting the driver to upcoming hazards which they may be unaware, or negatively, for example, by distracting the driver and disrupting their ability to complete the driving task. It was decided, however, after considerable reflection that the inclusion of this actor would not contribute to the analysis in any meaningful way. Passengers can influence drivers' decisions during all stages of a journey, regardless of road type or specific manoeuvre the drivers are currently engaged in, in a non-predictable way. Furthermore, passengers will not be present for all journeys a driver completes, and as such cannot be seen as a consistent constraint. The UK Department for Transport (2005) suggests that up to $89 \%$ of car journeys are single occupancy, although this figure varies considerably based on geographical location. Although passengers may influence fuel use to a limited extent, the lack of consistency and predictability meant that this category was not taken forward.

An excerpt of the competed SOCA-CAT analysis is presented in Fig. 4; the complete SOCA-CAT is presented within Online Appendix 4. It can be seen that for some functions, only one actor is present, for example, "display vehicle speed" is a function solely performed by the on-board displays, whereas a function such as "most fuel-efficient path" is constrained by on-board computers, on-board sensors, infrastructure, other road users and the law. The SOCA analysis highlighted the role that different agents can play in day-to-day driving fuel use and presents a myriad of opportunities for targeting future interventions. As each of the identified agents impacts fuel economy to some extent, the SOCA-CAT identified the tasks whereby in-vehicle interventions would be potentially most beneficial.

\subsection{Worker competency analysis (WCA)}

As the final stage of the CWA, WCA proceeds to consider the abilities and behaviour of the agents completing the work. Typically, this stage is considered using the skills, rules, knowledge (SRK) framework (Rasmussen 1974). As such, this stage can be seen to be shifting towards the psychological constraints of users as opposed to the physical and design constraints of the system considered previously (Kilgore and St-Cyr 2006). Vicente (1999) proposed the use of the SRK Taxonomy, which maps out the behaviour and cognitive processes that an individual may manifest when completing work-based activities. The SRK taxonomy considers that human control behaviour can be classified under three distinct levels. Skills-based behaviour (SBB) is classified as automatic responses to environmental stimuli, often without the need for individuals' direct attention. 


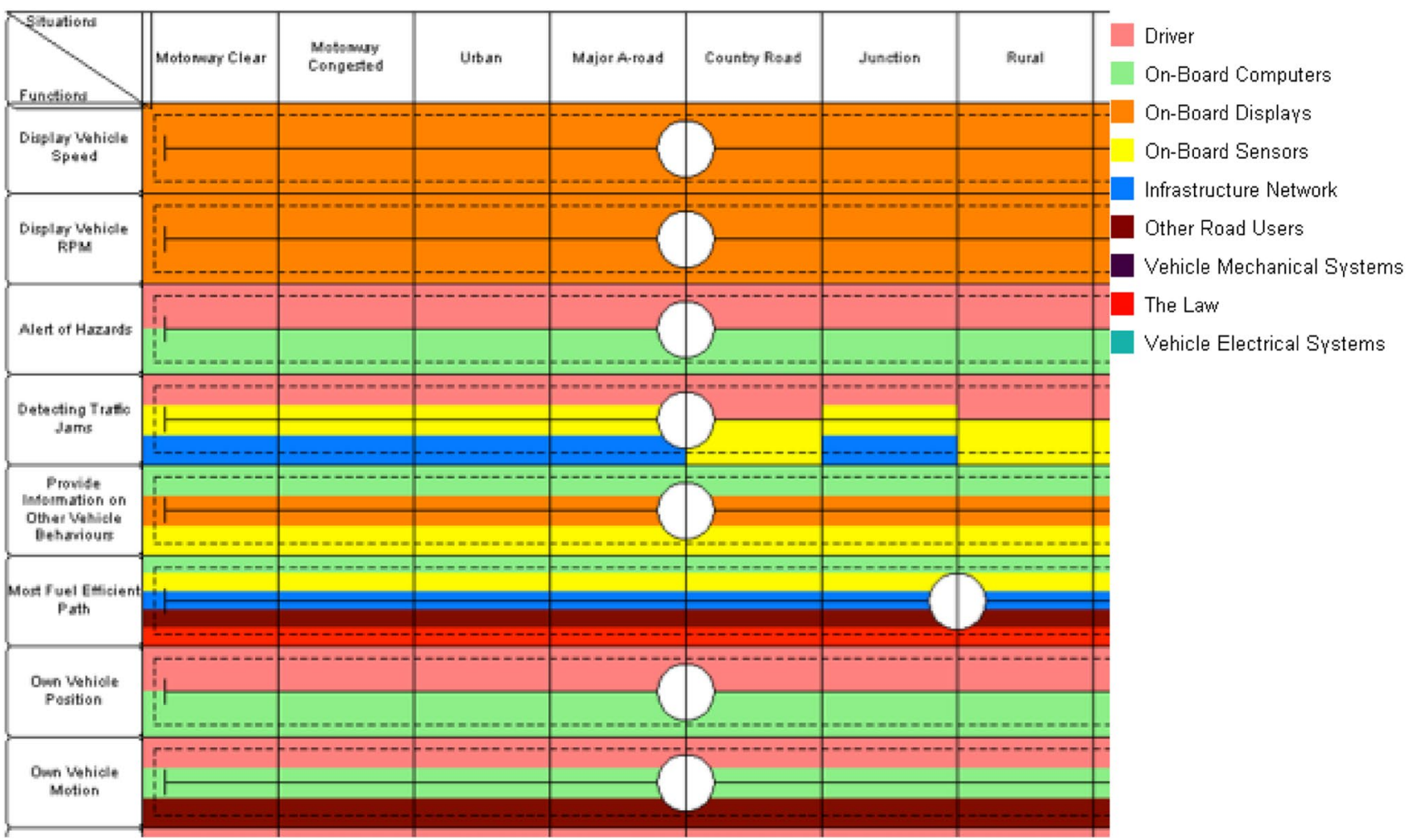

Fig. 4 An excerpt from the completed SOCA-CAT analysis of the agents involved in fuel-efficient driving, including legend

Rules-based behaviour (RBB) is based on linking perceptual cues to a desired outcome, following set guidelines and rules. Unlike SBB, RBB involves active decision-making, allowing an individual engaged in such behaviour to vocalise their intentions and behaviour. Knowledge-based behaviour (KBB) can be seen as the deployment of extensive and complex reasoning to find potential solutions to a problem. The use of KBB is slower and considerably more effortful than either SBB or RBB due to the need for extensive attentional focus. Tasks are not necessarily set at a given level of the taxonomy, but are dependant on users' ability and experience. Novice users may be forced to rely on KBB as they are unfamiliar with a task, whereas more experienced users may to be able to use RBB as they have greater familiarity with the system and its functioning. Expert users may be able to utilise SBB for some activities if they have had extensive experience and/or training. Previous research has identified that the mapping of expertise to the SRK taxonomy can be highly beneficial to the development of novel training regimes (Fleming and Pritchett 2016).

Although it is typical that the SRK taxonomy is developed using the decision ladders (McIlroy and Stanton 2015a, b), due to prior work, these were not considered within the current study. An alternative approach is to use the ObjectRelated Processes layer, presented within the abstraction hierarchy (McIlroy and Stanton 2011; Stanton and Bessell
2014). This approach can be seen as beneficial as it directly builds on insights gained previously within the CWA, including the CAT and SOCA-CAT. Table 3 presents a subset of the generated SRK taxonomy using this approach. From this table, it is clear that techniques that increase drivers' skill level, operating within the SBB level, either as a result of increased experience or greater information provision, will enable users to make more environmentally conscious decisions. Further work will be required to design and develop interfaces that provide sufficient information to fulfil these requirements but do not provide excessive and/or redundant information. Previous research (Kalyuga et al. 1997) has indicated that too much information can often be just as detrimental to user performance as insufficient information.

\subsection{Generating specifications}

Using the CWA approach, this paper has identified the constraints that operate around a system designed to reduce the fuel use of day-to-day driving. Insights generated within this analysis can be used to directly inform the specifications of the required system. Championing the positive role CWA can play in devising requirement specifications is not novel and has been discussed at length by McIlroy and Stanton (2012). They propose that as the WDA stage of the CWA process, the abstraction hierarchy offers a focus on what 


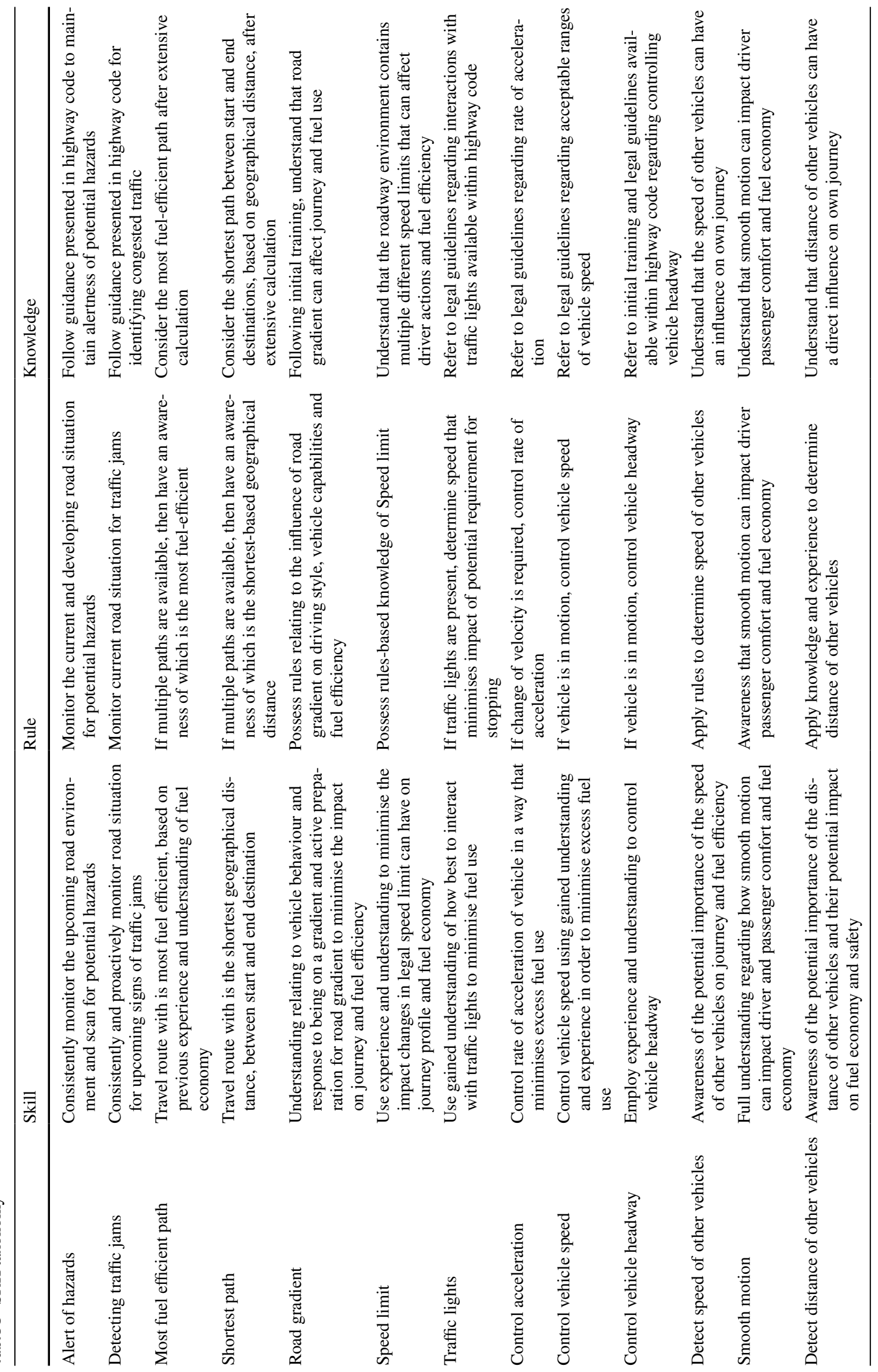


the system should achieve, independent of how these goals should be achieved; considerable parallels can be drawn to industrial requirement specification documents. This can be seen as a expansion on the work of Vicente (1999), who argues that the early stages of the CWA process, including the WDA, are independent of the users, their skills and any automation that may exist within the system. Despite this potential link, however, few direct examples of the use of CWA to devise system specifications exist within the literature. The work that has been conducted (Naikar and Sanderson 1999, 2001; Naikar 2006) has focused primarily upon the military domain. Taking ideas generated within CWA forward towards a considerably less prescribed domain, whereby users have considerable freedom in their actions, such as is the case when considering fuel-efficient driving is a great challenge. McIlroy and Stanton (2015a) argue that, in addition to the WDA stage, the WCA stage of CWA can provide valuable insight when designing specifications. McIlroy and Stanton (2015a) report that across the literature, there is considerable variation in the individuals' use of the different stages of the CWA process in informing design. They argue, however, that despite a step-by-step procedure for progressing CWA not being available, indeed perhaps not even possible, the use of the CWA process as a whole can be used to elucidate design. McIlroy and Stanton (2015b) advocate that using all CWA phases is required to achieve best results, as individual phases of the analysis cannot adequately support the perspectives of designers and developers.

Taking the ideas of this paper forward into designing suitable interfaces to support fuel-efficient driving, we can start to consider how each component of the completed CWA can inform design decisions. To start this process, it is possible to consider the different inputs a driver could make to control the vehicle, or directly request information from the vehicle. These considerations focused on speech requests, direct physical control and in-vehicle automation. Subsequently, the possible outputs a vehicle could make in response to drivers' requests, including how the vehicle can provide information and feedback to the driver, focussing on the sensory modalities of visual feedback, auditory feedback and haptic feedback was considered. Finally, insight relating to the external environment was examined for each stage of the CWA process. This focused on insights relating to the role of infrastructure items and a general category of "other" elements including weather conditions that could influence the driver and fuel economy. Table 4 presents the compiled information gained from this specification generation activity. As can be seen, not all stages of the CWA inform each of the generated input/output modalities, however all stages of the analysis offer unique insight that would not have been obtained should that stage not have been completed.

With this table in place, it is possible to identify a series of case studies whereby information or feedback could be provided to the driver. Working through Table 4, a series of case studies were conducted to identify the way in which the CWA could help inform specifications development. Three exemplar situations are presented in Table 5. As can be seen, the different stages of the CWA process provide qualitatively different insights that can be used to inform future development. Supporting previous research, the most significant information was generated within the initial WDA stage (McIlroy and Stanton 2012). Despite this, all stages actively contributed to the understanding of the fuel-efficient driving task (McIlroy and Stanton 2015b). Although limited insights were gathered from the StrA stage, this can be seen as a consequence of the prescribed nature of driving, with set operations being required to achieve set goals. Should the task under examination have greater freedom in achieving goals, there is no doubt this stage of the analysis would offer greater insights. Although these case studies are not the focus of the current paper, which seeks to document the development of the CWA, it is clear that the knowledge gained from a complete CWA can assist in the development of specifications for required in-vehicle interfaces across a variety of different road-based scenarios. Once fully developed, these in-vehicle interfaces can be taken forward for further empirical evaluation and testing.

\section{Conclusions}

This paper analysed the constraints that operate around the use and development of technology supporting fuel-efficient driving by the development of a complete cognitive work analysis. An initial abstraction hierarchy was presented, which documented the main objectives of the system, the metrics for judging success, considered the processes that each of these items undertook, and decomposing the physical objects that played a role in the system. Following this development, a contextual activities template was documented, decomposing the constraints, both spatial and temporal that acted on the system. Potential tasks a driver could be faced with were considered and a series of simplified flow maps constructed, examining the steps that a driver could go through to achieve a set target end state. In order to consider the role that different agents can take within a given scenario, a SOCA was produced considering both human and non-human agents that can influence fuel economy. Finally, a workers' competency analysis was completed, using the SRK taxonomy to examine the different actions experts and novices can take when faced with everyday driving situations.

Future work will seek to build on the current analysis by developing a series of potential interfaces based upon the introduce thought experiments to support fuel-efficient driving. These interfaces will be developed with the aid of 


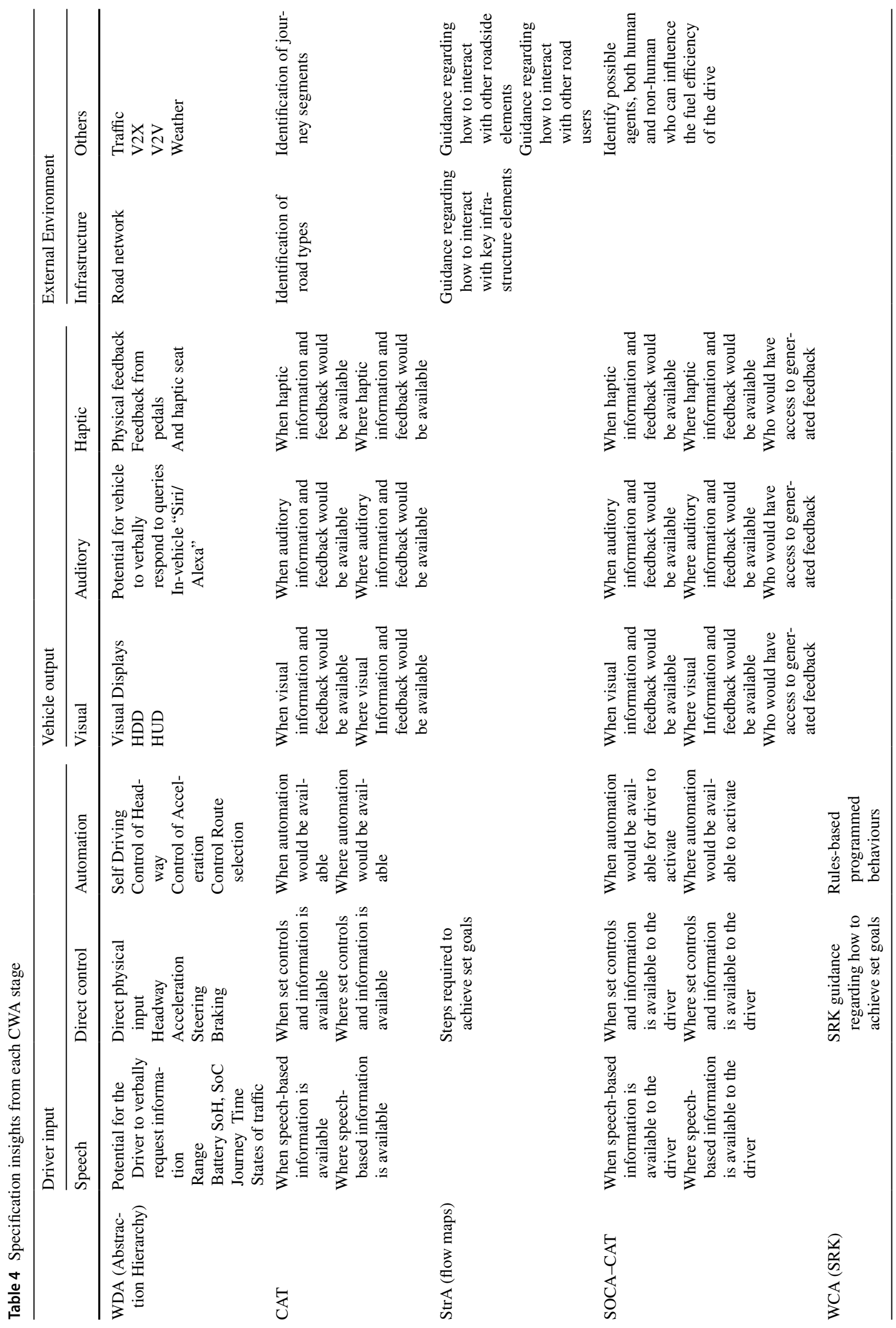




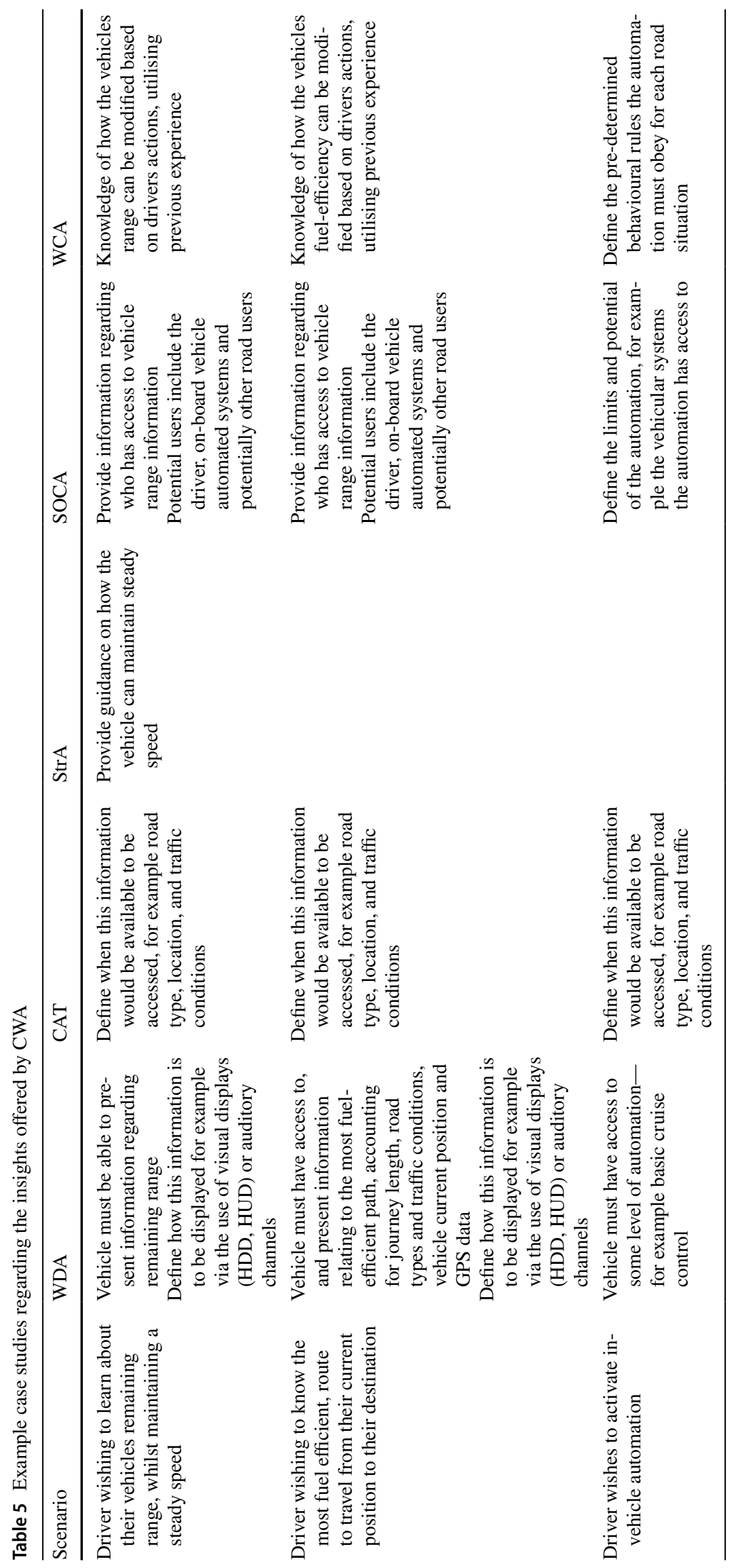


expert and novice drivers, and tested both in simulator and on-road. From the current analysis, it is argued that CWA provides a usable and accessible approach for mapping the constraints faced by users and acts as an approach that can inform future interface development and provide the basis for specification documentation.

The CWA approach brought forward a technologically agnostic tool to consider the requirements of fuel-efficient driving, highlighting the constraints that exist around this approach to driving, both in relation to the general driving task and in specific road situations. The use of CWA also allowed the identification and consideration of a variety of agents, both human and non-human, which can influence fuel use. Although the analysis highlighted that the driving task is largely prescriptive, with set mechanical operations required to control the vehicle and achieve set goals, opportunities for fuel-saving interventions were identified, primarily through the use of information provision. Greater knowledge of upcoming road events can enable drivers to react earlier, encouraging a more refined driving style, and potentially reducing the amount of fuel consumed each trip. Although the relative fuel savings of such actions are small, were these actions consistently repeated across all drivers, pollution and fuel use could drop significantly.

Acknowledgements This work was funded by the UK Engineering and Physical Sciences Research Council (EPSRC) grant EP/N022262/1 "Green Adaptive Control for Future Interconnected Vehicles" (http:// www.g-active.uk). The authors would like to offer thanks to all participants who gave their time to participate within the workshops presented within the current work. The authors would also like to thank D. T. Fay for assistance in generating the Abstraction Hierarchy figure presented within the appendix of this manuscript.

Open Access This article is distributed under the terms of the Creative Commons Attribution 4.0 International License (http://creativeco mmons.org/licenses/by/4.0/), which permits unrestricted use, distribution, and reproduction in any medium, provided you give appropriate credit to the original author(s) and the source, provide a link to the Creative Commons license, and indicate if changes were made.

\section{References}

Ahlstrom U (2005) Work domain analysis for air traffic controller weather displays. J Saf Res 36(2):159-169

Allison CK, Stanton NA (2019) Eco-driving: the role of feedback in reducing emissions from everyday driving behaviours. Theor Issues Ergon Sci. https://doi.org/10.1080/1463922x.2018.14849 67 (just-accepted)

Barkenbus JN (2010) Eco-driving: an overlooked climate change initiative. Energy Policy 38(2):762-769

Bin S, Dowlatabadi H (2005) Consumer lifestyle approach to US energy use and the related $\mathrm{CO}_{2}$ emissions. Energy Policy 33(2):197-208

Birrell SA, Young MS, Jenkins DP, Stanton NA (2012) Cognitive work analysis for safe and efficient driving. Theor Issues Ergon Sci 13(4):430-449
Cacciabue PC, Martinetto M (2006) A user-centred approach for designing driving support systems: the case of collision avoidance. Cogn Technol Work 8(3):201-214

Cacciabue PC, Saad F (2008) Behavioural adaptations to driver support systems: a modelling and road safety perspective. Cogn Technol Work 10(1):31-39

Carsten OM, Tate FN (2005) Intelligent speed adaptation: accident savings and cost-benefit analysis. Accid Anal Prev 37(3):407-416

Cornelissen M, Salmon PM, Jenkins DP, Lenné MG (2013) A structured approach to the strategies analysis phase of cognitive work analysis. Theor Issues Ergon Sci 14(6):546-564

Davidsson S, Alm H (2014) Context adaptable driver information-or, what do whom need and want when? Appl Ergon 45(4):994-1002

Department for Transport (2005) Personalised travel planning: evaluation of 14 pilots part funded by DfT, availible from https://webar chive.nationalarchives.gov.uk/20110504142036/http://www.dft. gov.uk/pgr/sustainable/travelplans/ptp/personalisedtravelplannin gev577

Dietz T, Gardner GT, Gilligan J, Stern PC, Vandenbergh MP (2009) Household actions can provide a behavioral wedge to rapidly reduce US carbon emissions. Proc Natl Acad Sci 106(44):18452-18456

Ehsani M, Gao Y, Longo S, Ebrahimi K (2018) Modern electric, hybrid electric, and fuel cell vehicles. CRC, Boca Raton

Fénix J, Sagot JC, Valot C, Gomes S (2008) Operator centred design: example of a new driver aid system in the field of rail transport. Cogn Technol Work 10(1):53-60

Fidel R, Pejtersen AM (2004) From information behaviour research to the design of information systems: the cognitive work analysis framework. Inf Res Int Electron J 10(1):210

Fleming E, Pritchett A (2016) SRK as a framework for the development of training for effective interaction with multi-level automation. Cogn Technol Work 18(3):511-528

Gillespie TD (1992) Fundamentals of vehicle dynamics, vol 114. SAE technical paper

Hill N, Brannigan C, Smokers R, Schroten A, van Essen H, Skinner I (2012) eu Transport ghg: routes to 2050. ii. Final project report funded by the European Commission's Directorate-General Climate Action, Brussels

Horrein L, Bouscayrol A, Cheng Y, Dumand C, Colin G, Chamaillard Y (2016) Influence of the heating system on the fuel consumption of a hybrid electric vehicle. Energy Convers Manage 129:250-261

Houghton RJ, Baber C, Stanton NA, Jenkins DP, Revell K (2015) Combining network analysis with cognitive work analysis: insights into social organisational and cooperation analysis. Ergonomics 58(3):434-449

Jamson AH, Hibberd DL, Merat N (2015) Interface design considerations for an in-vehicle eco-driving assistance system. Transp Res Part C Emerg Technol 58:642-656

Jenkins DP, Stanton NA, Salmon PM, Walker GH, Young MS (2008) Using cognitive work analysis to explore activity allocation within military domains. Ergonomics 51(6):798-815

Kalyuga S, Chandler P, Sweller J (1997) Levels of expertise and useradapted formats of instructional presentations: a cognitive load approach. In: Jameson A, Paris C, Tasso C (eds) User modelling: proceedings of the sixth international conference (UM 97). Springer, New York, pp 261-272

Kant V (2017) Revisiting the technologies of the old: a case study of cognitive work analysis and nanomaterials. Cogn Technol Work 19(1):47-71

Kilgore R, St-Cyr O (2006) The SRK inventory: a tool for structuring and capturing a worker competencies analysis. Proceedings of the human factors and ergonomics society annual meeting, vol 50. SAGE, Los Angeles, pp 506-509 
LaClair TJ, Verma R, Norris S, Cochran R (2014) Fuel economy improvement potential of a heavy duty truck using $\mathrm{V} 2 \mathrm{x}$ communication. National Transportation Research Center (NTRC), Oak Ridge National Lab (ORNL), Oak Ridge

Lintern G, Cone S, Schenaker M, Ehlert J, Hughes T (2004) Asymmetric adversary analysis for intelligent preparation of the battlespace (A3-IPB). United States Air Force Research Department Report

McIlroy RC, Stanton NA (2011) Getting past first base: going all the way with cognitive work analysis. Appl Ergon 42(2):358-370

McIlroy RC, Stanton NA (2012) Specifying the requirements for requirements specification: the case for work domain and worker competencies analyses. Theor Issues Ergon Sci 13(4):450-471

McIlroy RC, Stanton NA (2015a) A decision ladder analysis of ecodriving: the first step towards fuel-efficient driving behaviour. Ergonomics 58(6):866-882

McIlroy RC, Stanton NA (2015b) Ecological interface design two decades on: whatever happened to the SRK taxonomy? IEEE Trans Hum Mach Syst 45(2):145-163

McIlroy RC, Stanton NA, Harvey C (2013) Getting drivers to do the right thing: a review of the potential for safely reducing energy consumption through design. IET Intel Transp Syst 8(4):388-397

Miller SA, Heard BR (2016) The environmental impact of autonomous vehicles depends on adoption patterns. Environ Sci Technol 50(12):6119-6121

Naikar N (2006) Beyond interface design: further applications of cognitive work analysis. Int J Ind Ergon 36(5):423-438

Naikar N (2013) Work domain analysis: concepts, guidelines, and cases. CRC, Boca Raton

Naikar N, Lintern G (2002) A review of "Cognitive work analysis: towards safe, productive, and healthy computer-based work" by Kim J. Vicente. Int J Aviat Psychol 12(4):391-400

Naikar N, Sanderson PM (1999) Work domain analysis for training-system definition and acquisition. Int J Aviat Psychol 9(3):271-290

Naikar N, Sanderson PM (2001) Evaluating design proposals for complex systems with work domain analysis. Hum Fact 43(4):529-542

Naikar N, Pearce B, Drumm D, Sanderson PM (2003) Designing teams for first-of-a-kind, complex systems using the initial phases of cognitive work analysis: case study. Hum Fact J Hum Fact Ergon Soc 45(2):202-217

Naikar N, Moylan A, Pearce B (2006) Analysing activity in complex systems with cognitive work analysis: concepts, guidelines and case study for control task analysis. Theor Issues Ergon Sci 7(4):371-394

Oinas-Kukkonen H, Harjumaa M (2009) Persuasive systems design: key issues, process model, and system features. Commun Assoc Inf Syst 24(1):28

Pampel SM, Jamson SL, Hibberd D, Barnard Y (2017) The activation of eco-driving mental models: can text messages prime drivers to use their existing knowledge and skills? Cogn Technol Work 19(4):743-758

Rasmussen J (1974) The human data processor as a system component: bits and pieces of a model (Report no. Ris $\varnothing-M-1722)$. Danish Atomic Energy Commission, Roskilde

Rasmussen J (1986) Information processing and human-machine interaction. An approach to cognitive engineering, North-Holland series in system science and engineering. Elsevier, Amsterdam, Netherlands

Rasmussen J, Pejtersen AM, Schmidt K (1990) Taxonomy for cognitive work analysis. Ris $\emptyset$ National Laboratory Press, Roskilde (Risø report M-2871)
Rasmussen J, Pejtersen AM, Goodstein LP (1994) Cognitive systems engineering. Wiley, New York

Robinette D, Grimmer M, Horgan J, Kennell J, Vykydal R (2011) Torque converter clutch optimization: improving fuel economy and reducing noise and vibration. SAE Int J Eng 4(1):94-105

Sharp TD, Helmicki AJ (1998) The application of the ecological interface design approach to neonatal intensive care medicine. Proc Hum Fact Ergon Soc Annu Meet 42(3):350-354

Stanton NA, Bessell K (2014) How a submarine returns to periscope depth: analysing complex socio-technical systems using cognitive work analysis. Appl Ergon 45(1):110-125

Stanton NA, McIlroy RC (2012) Designing mission communication planning: the role of rich pictures and cognitive work analysis. Theor Issues Ergon Sci 13(2):146-168

Stanton NA, McIlroy RC, Harvey C, Blainey S, Hickford A, Preston JM, Ryan B (2013) Following the cognitive work analysis train of thought: exploring the constraints of modal shift to rail transport. Ergonomics 56(3):522-540

Stanton NA, Harris D, Starr A (2016) The future flight deck: modelling dual, single and distributed crewing options. Appl Ergon $53: 331-342$

Strömberg H, Karlsson IM, Rexfelt O (2015) Eco-driving: drivers' understanding of the concept and implications for future interventions. Transp Policy 39:48-54

Takezaki J, Ueki N, Minowa T, Kondoh H (2000) Support system for safe driving. Hitachi Rev 49(3):107

Thornton J, Covington H (2015) Climate change before the court. Nat Geosci 9:3

Tulusan J, Staake T, Fleisch E (2012) Providing eco-driving feedback to corporate car drivers: what impact does a Smartphone application have on their fuel efficiency? In: Proceedings of the 2012 ACM conference on ubiquitous computing. ACM, pp 212-215

Tunnell J, Asher ZD, Pasricha S, Bradley TH (2018) Toward improving vehicle fuel economy with ADAS. SAE Int J Connect Automat Veh 1(12-01-02-0005):81-92

van Westrenen $F$ (2011) Cognitive work analysis and the design of user interfaces. Cogn Technol Work 13(1):31-42

Vandenbergh MP, Steinemann AC (2007) Carbon-neutral individual. NYUL Rev 82:1673

Vandenbergh MP, Barkenbus J, Gilligan J (2007) Individual carbon emissions: the low-hanging fruit. UCLA L Rev. 55:1701

Vicente KJ (1999) Cognitive work analysis: towards safe, productive, and healthy computer-based work. LEA Press, Mahweh

Wu Y, Zhao X, Rong J, Zhang Y (2017) How eco-driving training course influences driver behavior and comprehensibility: a driving simulator study. Cognition, Technology \& Work 19(4):731-742

Yan X, Fleming J, Lot R (2018) A/C energy management and vehicle cabin thermal comfort control. IEEE Trans Veh Technol 67(11):11238-11242

Young MS, Birrell SA, Stanton NA (2011) Safe driving in a green world: a review of driver performance benchmarks and technologies to support 'smart' driving. Appl Ergon 42(4):533-539

Publisher's Note Springer Nature remains neutral with regard to jurisdictional claims in published maps and institutional affiliations. 